\title{
[A] DESTRUIÇÃO ANIMOT [RELAÇÕES ENTRE A FILOSOFIA E A PSICANÁLISE EM DERRIDA]
}

\author{
JoÃo C. GALVÃo JR.
}

João C. Galvão Jr. Universidade Federal Fluminense (UFF), Doutor pelo Departamento de Ciência Política, Niterói/RJ, Brasil.
RESUMO: Trabalhamos com o quase conceito animot de Derrida, narrando sua experiência trágica entre o pensamento poético e o saber filosófico, e sua leitura deste quase conceito na teoria psicanalítica, forjando no pensamento da diferença a cena da escritura - inconsciente como escritura - e este outro do outro [que chama] [de] animot, que só se distingue na escritura e não da voz revelada. Nessa leitura, para [o] animot tudo é permitido.

Palavras-chave: desconstrução; destruição; escritura; experiência trágica; inconsciente animot.

ABSTRACT: The animot destruction [The relationships between philosophy and psychoanalysis in Derrida].We have been working with Derrida's almost concept animot, narrating his tragic experience between poetic thought and philosophical knowledge and his reading of this almost concept in psychoanalytic theory, faking the writing scene in the thought of difference - unconscious as writing - and this other one from the other one [which is called] animot, which is only distinguished in writing and not from the revealed voice. In this reading, everything is permitted for animot.

Keywords: deconstruction; destruction; writing; tragic experience; unconscious animot.

DOI - http://dx.doi.org/10.1590/1809-44142017003007 
Por ter, como ninguém, cultivado sua alma, que já era rica, ele [o poeta] alcança o desconhecido, e quando, assombrado, terminar por perder a consciência de suas visões, ele as terá visto! Que se arrebente no salto rumo às coisas inauditas e inomináveis: outros trabalhadores horríveis virão; e começarão pelos horizontes onde o outro sucumbiu!

A. Rimbaud

\section{INSTINTO [DO] ANIMAL AUTOBIOGRÁFICO COMO EXPERIÊNCIA TRÁGICA}

Em um texto autobiográfico, Derrida segue com sua narrativa num teatro sem palco nem cortina até [com] a morte - finitude - [do] animot ${ }^{1}$. Talvez [o] animot de Derrida se coloque do lado da morte - momentos vividos, as coisas recolhidas. O animal que logo sou [L'animal que donc je suis]: já na leitura do título em francês de seu texto, o narrador joga com as palavras de forma sutil e profunda - quando je suis é a primeira pessoa do presente do indicativo do verbo être [ser] e do verbo suivre [seguir]. O animal é um ser? 0 ser é um animal? $\mathrm{O}$ animal segue o ser? $\mathrm{O}$ ser [per]segue o animal? [O] animot [des] habita o nomeado ser. $\mathrm{O}$ instinto do animal autobiográfico [l'instinct de l'animal autobiographique] recebe hospitalidade do Eu-do-outro, diferente de "Eu é um outro" (RIMBAUD, 2009, p. 38), quando permanece na ordem da fala, de uma linguagem que habita a nomeada Casa [linguagem humana]; quando se expressa na escritura como ato passa ser hostilizado. Eu observo o animal em mim mesmo - observo o outro em mim porque Eu é um outro [“O 'eu' é qualquer um, 'eu' sou qualquer um..." (DERRIDA, 2006, p. 75)]. Mas este animal interior [discurso interno / movimentos internos] em mim não tem face - é outro do outro - linguagem das coisas: nas periferias de uma tal reflexão se encontraria a coisa (DERRIDA, 2006). Este instinto do animal autobiográfico não tem face [é outro do outro] - sem face. Porque animot é um outro do outro. Esse título, "animal”, evocado por Derrida, cruza [o] animal e a autobiografia, bestiário pessoal que se apresenta num sonho de hospitalidade absoluta. Ou seja: “Como acolher ou liberar tantos animots em mim?” (DERRIDA, 2006, p. 60). Liberação [libertação] que pensa [o] animot como ato e não como verbum. As coisas da natureza desafiam o narrador com poder de responder - numa relação de forças; resistindo com sua força própria - [o] instinto do animal me olha [quando há o olhar do instinto não há "inconsciente humano"]. [O] animot é o próprio movimento da liberdade; e essa liberdade que a palavra, no momento de suprimi-la [eliminar], apontava com a fala [discurso / mensagem]? Filho da dor e ruína de sua Casa: [o] animot; na reflexão sobre essa coisa e até na análise de um saber filosófico que del[e] se faz, tratar-se-á não do erro, mas da liberdade em ato. Seu sentido só pode aparecer diante do Filósofo, isto é, daqueles que são capazes de conhecer sua natureza, dominá-la em seu não-ser e de passar à frente na direção da verdade. E enquanto [o] animot era outrora o estranho em relação ao nomeado "Ser", ei-lo agora dominado na própria verdade deste discurso; mais neutralidade, uma vez que nele se descobrirão as verdades do homem, separando seus movimentos internos do seu Eu. Essa estranha face passa a assumir as virtudes de espelho; "onde uma certa cena autobiográfica se dispõe é necessário uma psique [psyché]" (DERRIDA, 2006, p.76) fraturando o reflexo desse espelho ${ }^{2}$, suas imagens interiores e arcaicas. [Des]ligad[o] a uma civilização [culture] e ao seu mal-estar [la malséance], [o] animot faz surgir um mundo interior de maus instintos, de perversidade, um bestiário pessoal, apresentando uma inacessibilidade das coisas internas, instante das pré-coisas que dá todo seu sentido à liberdade do homem. O nomeado estádio do espelho [stade $d u$ miroir $]^{3}$, sua identidade e forma - com todas as suas conseqüências políticas - são fraturados pelo

${ }^{1}$ Animot pronuncia-se em francês da mesma forma que animaux; diferenciando-se somente nas sombras da escritura e não na voz revelada.

2 Psyché em francês: 1 Grande espelho; 2 . Psiquê.

${ }^{3}$ Derrida faz referência ao "estádio do espelho" de J. Lacan, Le stade du miroir comme formateur de la fonction du Je (1936-1949) In Écrits. Paris: Seuil, 1966. [O estádio do espelho como formador da função do Eu. In: Escritos. Trad. Vera Ribeiro. Rio de Janeiro: JZE, 1998]. 
[não]lugar de não-poder animot - animal incapaz ["que daria conta da necessidade de rasurar o 'ser'” (DERRIDA, 2006, p. 63)] ou excluído por força de lei(X); em seu caráter destrutivo apresenta "outra coisa" para além da questão do nomeado "ser"; [um] animal capaz de rasurar este Nomeado num operador de escritura [opérateur d'écriture (DERRIDA, 2006)] - [o] animot como escritura interior.

Mas, para além das palavras, [a] coisa que está acontecendo em Derrida é [o] animot. Queremos dizer com isso que é numa autobiografia - instinto do animal autobiográfico - que Derrida apresenta sua loucura, sua experiência trágica com a literatura, poesia, para alguns, considerada doença mental; "pois o pensamento do animal, se pensamento houver, cabe à poesia, eis aí uma tese, e é disso que a Filosofia, por essência, teve de se privar. É a diferença entre um saber filosófico e um pensamento poético" (DERRIDA, 2006, p. 23). Dirse-ia que uma fada entrou naquela Casa...

\section{[O] ANIMAL [DES] HABITA NO HOMEM}

Pensar o homem de um lado e o animal do outro já é metafisicamente tentar resolver o problema levantado pelo savoir philosophique. Derrida, ao contrário, pensa o animal no homem - da sua falta de logos. $\mathrm{O}$ animal dentro de nós [outros dos outros], "e o logocentrismo é antes de mais nada uma tese sobre o animal, sobre o animal privado de logos, privado do poder-ter o logos: tese, posição ou pressuposição que se mantém de Aristóteles a Heidegger, de Descartes a Kant, Lévinas a Lacan" (DERRIDA, 2006, p. 48).

$O$ animal passa pelo estranho estrangeiro do deserto, [des] habita uma língua que não é dele [come por dentro], não possui face e nem linguagem humana [insconsciente humano]; [des] habita no homem - o malestar de um animal dentro do homem que não quer se domesticar. Que animal? O outro [do outro] que olha em silêncio pelo olhar do animal, um "olhar de vidente" [un regard de voyant] (DERRIDA, 2006, p. 18); [o] animal agita-se nas profundezas ou ganha de um salto a cena; abertura material de um pensamento poético; [o] animal dá ritmo à ação; busca sua alma, experimenta e a transforma numa alma monstruosa - [o] animal se faz vidente (RIMBAUD, 2009), alcançando o desconhecido, estranho, perdendo a consciência e conseguindo ver, grande maldito - Aquilo que [des] habita a alma. [O] animot, antes de mais nada, é uma figura da natureza. Esta radicalização do pensamento derridiano toca e cheira as margens de uma posição clandestina e obscura, não neutral, assinada pelo homem [animal autobiográfico]. Acreditamos que este instinto do animal ou instintual animal na re-abertura das coisas nomeadas encontra-se num movimento radicalizado da desconstrução - momento em que sua alma e corpo entremesclam-se na destruição das representações.

Nesse momento ou pelo menos nesse texto - texto poético, arrisco - seu pensamento está bem próximo de um caráter destrutivo das coisas nomeadas, mais de uma língua ["plus d'une langue"] ${ }^{4}$ que cria aberturas em sua estilística ou arte de escrever sobre o pensamento da desconstrução. [A] desconstrução aqui não teria face ou faces (submetida ao discurso humanista, discurso do sujeito...), mas a singularidade da escrita deste animal instintual autobiográfico - ela mesma, mais de uma língua, aberta ao indeterminado [“...um animal ainda indeterminado..." (DERRIDA, 2006, p. 17)]; ou mesmo, as próprias palavras (destruição versus desconstrução) deixariam de ter algum sentido e remeteriam direto a experiência da[s] coisa[s] animot. Linguagens da natureza no interior dos estados-da-alma - alma. Linguagens no mundo que esta alma habita. [O] animot [des] habita a Casa da linguagem? Qual linguagem? O que é linguagem? Casa? Qual Casa? Deserto. A nomeada "Casa" pertence a alguém? Estas coisas silenciosamente se arrastam, inquietantemente, estranhamente como diferença no pensamento como um resistir que está para sua natureza interior o que faz pulsar [no] animot. Nesta estilística, neste instante da escritura, forjando quase conceitos internos e potentes como "o animal que logo sou", "sou" animot [des]ligado à animalidade estrangeira que [des] habita esta nomeada Casa. [O] animot faz parte da nomeada Casa? É inquietante? Estranho? Estrangeiro? Ao mesmo tempo, habita a Casa e não habita - [des] habita.

Questões ambivalentes que marcam o discurso filosófico, para não deixar de registrar o político [do] animot que pulsa na diferença e é eliminado [exterminado] pelo discurso das representações significantes da estrutura [as máquinas eliminam os traços]; políticas que marcam o pensamento deste outro do outro

\footnotetext{
4 "Se tivesse de arriscar, Deus me valha, uma única definição da desconstrução, breve, elíptica, econômica como uma palavra de ordem, diria sem frase: mais de uma língua" ["Si j'avais à risquer, Dieu m'en garde, une seule définition de la déconstruction, brève, elliptique, économique comme un mot d'ordre, je dirais sans phrase: plus d'une langue"]. DERRIDA, J. Mémoires pour Paul de Man, Galillé, 1988, p. 38.
} 
[animalidade no homem ou animot] que resiste na diferença material [diferança]; outro do outro que, diante do discurso desta estrutura, não tem face - outro do outro que não tem face [não é considerado humano]; o nomeado estranho [estrangeiro] ou inumano; diferença de dentro, do interior, de um aparelho da alma que resiste à morte na escritura [morremos e somos rememorados]. Talvez se coloque do lado da morte. Somente [o] animot e só ele, em sua solidão [deserto], solidão na escritura e resistência política - mas a esta escritura como força interior - escritura interior - que pode ser rememorada, salvando os mortos - abertura da História.

Posição inquietante, trabalho da diferença, estrangeira [diferença estranha e estrangeira]: desconstrução estrangeira; destruição estrangeira; ambivalência estrangeira. animot inquietante-silencioso [silêncio que faz tremer] - mais de uma língua - um ruído vago, um murmurar distante... A natureza acorda e de raios se embriaga - o discurso filosófico passa Une Saison en Enfer com [o] animot.

\section{LINGUAGEM ANIMAL [ANIMOT É ${ }^{5}$ DESTRUIÇÃo]}

"Mais de uma língua" [no] animot [linguagem animal] - estranha e silenciosa; interior silencioso irrepresentável. O que resta [resíduo] deste estranho silêncio que pulsa ${ }^{6}$ [no] animot cria uma abertura no político [pensamento ético-político]. Das figuras da natureza [linguagem das coisas], profundidade instintual [corporal ao psíquico no animot], as coisas retornam à sua força de desconstrução $e$ destruição; criando e forjando a diferença [para além do discurso da metafísica da diferença da nomeada "Casa"]. No deserto, mundo da natureza [coisas não nomeadas] não há nomes ["ausência do nome ou da palavra" (DERRIDA, 2006, p. 74)], mas energias [animalidade (DERRIDA, 2006, p. 75)] em suas retornanças. Este[s] animot retorna retornam em suas diferenças. Enfrentar a linguagem como algo puro [das coisas] e fazer com que ela caia em tremor ou num movimento repetido; como se a linguagem se tornasse animal [retorno da linguagem animot] na produção da diferença. Pensar esta diferença para além da linguagem humana e da repetição do mesmo. Estranho silêncio animot que faz tremer a ordem da linguagem humana; um silêncio não dito que trabalha a cada instante, não faz parte da comunidade da linguagem enquanto dimensão da Voz, a voz que nomeia. A linguagem animot repete a diferança em sua silenciosa irritabilidade interior [o animot como uma coisa que habita e não habita a "Casa" nomeada humana].

Não abandonar o discurso do pensamento metafísico; isso é uma posição estratégica de pensar resistências; por outro lado, manter essas silenciosas forças [sem repetir o mesmo de um "Nietzsche" aparentemente não religioso; duplo filosófico metafísico que repete o mesmo da religião "sem" religião]. Se existe um ou vários "Nietzsche(s)" aqui, ele se encontra nas relações de forças interiores dos animais; a "soltar de alguma maneira todos seus animais na Filosofia" (DERRIDA, 2006, p. 58); um "Nietzsche" que reanimaliza [réanimalise] o quase conceito da linguagem animal [linguagem das coisas] - proposta de uma outra linguagem - estranha ao saber filosófico. Pensamento das forças da [des]ordem de um inconsciente animot ${ }^{7}$ [um "Nietzsche" inconsciente no pensamento da diferença] mais profundo e terrível que faz tremer, do que o discurso do mundo externo "nietzscheano" ou que se auto-nomeia "pós-nietzscheano".

Existe uma violência no pensamento e na repetição da diferença e trabalho deste pensamento produzindo algo novo: [o] animot num nível inconsciente e vinculado à diferança. $\mathrm{O}$ registro destas forças destes quase conceitos passa aqui por um trabalho do inconsciente como escritura e força de resistência das coisas - as forças deixam marcas no interior [do] animot; no mundo das coisas, as coisas resistem a uma nomeada linguagem humana por um inconsciente como escritura que faz parte desse animot. "mais de uma língua" nas relações de forças destes quase conceitos forjados são forças constantes desta linguagem das coisas e este "mais" estando "além do bem e do mal": um "Nietzsche" mais profundo, silencioso e estranho - inconsciente animot - libertando o homem das amarras da linguagem. Com [o] animot, Derrida expressa e passa ser o grande representante de um pensamento pós-nietzscheano numa outra filosofia ou pensamento da diferença.

\footnotetext{
5 Terceira pessoa do presente do indicativo do verbo ser.

6 "...a animalidade, a vida do vivente se define como irritabilidade [irritabilité] apta a se mover, a se marcar a si-mesma, a se traçar..." DERRIDA, J. L'animal que donc je suis (1999). Paris: Galilée, 2006, p. 75.

${ }^{7}$ Acreditamos que quando Derrida faz sua crítica a Lacan, de uma "linguagem humana" [inconsciente humano] está colocando a problemática de um inconsciente animot.
} 
[O] animot é explorador de regiões desconhecidas; seu acontecimento como ato filosófico se dá para além da linguagem e das florestas sacralizadas; sua vida, uma série de fugas e retornos a Casa. Uma das coisas que caracteriza [o] animot é a insurreição da força, ou seja, no animal, uma certa força interior se desencadeia, força não dominada, não dominável em que faz [é] suas destruições - é destruição. A nomeada bio-política não é rompida por lutas bio-políticas; a[s] resistência[s] da experiência trágica [do] animot está [des]ligada à resistência pela destruição - já é destruição - e não às resistências da nomeada lutas bio-políticas. Queremos dizer com isso que é o caráter destrutivo [do] animot que fratura com as instâncias produtoras das práticas discursivas de um certo saber filosófico [político]. "é" não é um jogo de palavras; nem quer ser a palavra de todas as palavras - "é" é ato [ato do outro do outro] que destrói a palavra "ser"; em ato, "é" não passa pelo nomeado "ser". Discutindo palavras as coisas escapam ao saber filosófico, apresentando-se abertas ao pensamento poético e caráter destrutivo em ato - por isso - é destruição. Aquilo que "é", não é apenas uma certa derivação da palavra falada "ser", mas, flui em outra direção, desconstruindo e, em alguns casos, destruindo a palavra de todas as palavras [...]. O nomeado humano nesse saber, sua "essência", consiste em possuir palavras [...]. Aquilo que é o "ser" [do] animot, isto é, a entidade [irritabilidade], cria e forja uma alma [psíquico] escritural [alma na escritura] resistindo ao nomeado "ser"; carrega em seu interior: uma alma forjada na escritura e seu caráter destrutivo como experiência que passa pelo trágico ${ }^{8}$.

Nesse registro, Derrida se coloca do lado da morte [já com a morte], junto com Benjamin e Freud animot é destruição. As resistências habitam o interior. Ou seja: a resistência da alma [psíquico] [do] animot vem pelo caráter destrutivo [instintuais pulsionais de morte] e não alegremente em "lutas bio-políticas". Essa resistência da alma está entremesclada a um inconsciente escritural e morte. Resta que esse saber consiste em suprimir [o] animot dentro de nós, em reduzi-lo à inexistência, porque [o] animot é percebido pelos seus atos. O que está em causa nesse saber é vitória e submissão; o domínio que se pretende não é mais sobre seu erro, mas diz respeito à[s] força[s] desencadeada[s] no animot que deflagra seu ato de insurgir-se. Alguns diriam que tudo é uma questão de poder - mas a linguagem animal é de alma para alma - o invisível "é".

\section{[0] ANIMAL COMO COISA EM ATO}

É essa linguagem das coisas ou deste quase conceito forjado para o pensamento da diferença - animot - que coloca como força constante a animalidade [tremor e terror] como algo invisível e silencioso, criando as aberturas materiais no instante $d a$ História.

Uma questão eminentemente ético-política: a eliminação [extermínio] destas irritabilidades [do] animot pelo discurso do pensamento metafísico que quer sempre em nome da vontade de verdade representar algo [pensamento da representação]. Descentralizando o nomeado humano [moderno sujeito] e considerado humano porque habita a "Casa" ou desconstruindo um pretenso discurso do Eu, a partir do Outro, constituise um Eu a partir do Outro. À "eliminação" deste nomeado humano é rotulada e hostilizada a desconstrução pelo pensamento da representação. Pelo contrário, ao expressar e trabalhar mais de uma língua [no] animot, resistindo a este pensamento metafísico que de forma "secularizada" tenta impor de forma autoritária sua suposta presença (DUQUE-ESTRADA, 2005), a diferença vem à tona expressando-se pela linguagem animot criando [a] diferença interior e silenciosa [tremor e terror]; alguma coisa estranha; alguma coisa que não será dita. [O] animot ao "falar" uma língua estrangeira - permanece ou não no [des] habitar desta "Casa". O nomeado "mal" pela linguagem humana seria esta coisa estrangeira que se enraivece inquietantemente no interior desta estrutura ["Casa"] que a cada instante pode ser desconstruída e destruída pelos inquietantes diferentes do pensamento da radical alteridade [outros do outros]: animot. Com o "quase conceito" animot, forjado no pensamento da diferença, rompe-se com o discurso totalizante ou visão de mundo. A natureza [do] animot coloca as coisas mais estranhas frente à racionalidade do discurso do humanismo, fazendo tremer esta estrutura sangrenta. No instante [do] animot já se passa ao ato [o animot sendo uma coisa em ato]. Essas coisas estranhas do movimento interno [do] animot que foram desencadeadas não remeteriam para uma Lei determinada do discurso humano [linguagem humana] como linguagem fônica. Pelo contrário: esse movimento interno destruiria com suas forças mais selvagens - puramente [divinamente] - com a cadeia de significantes representacionais. Lacan é desconstruído $e$ destruído por Derrida. Impulsos instintuais inerentes à própria natureza [do] animot. Algo ou alguma coisa indeterminado não vai ser domesticado [não há

${ }^{8}$ Diferenciamos aqui, tragédia de drama trágico. 
domesticação dos resíduos animot pelo nomeado "Ser"]; e, com isso, acha-se aberto o problema da eventual emancipação [do] animot em relação a essa forma de ser-saber; [o] animot é o não-poder aberto em ato na destruição do instante.

Nesta primeira leitura, o que estaria em jogo no caráter ético-político, seria o vínculo das coisas da natureza com um inconsciente animot [versus "inconsciente humano"] que não se esforça por outra coisa que não irromper e abrir seu caminho à consciência por meio de uma ação. [O] animot não é um nomeado "Ser"; não tem seu passe pela "Casa" do espírito [ou da repetição infernal do mesmo]. Essas forças são, antes de tudo: animot [compreender a natureza em sua alma mais profunda] - Satanas sum et nihil humani a me alienum puto ${ }^{9}$ o ato no qual [o] animot se torna infiel aos seus próprios instintos são sinais de humanismo. Mas, para [o] animot instintual tudo é permitido em ato.

\section{O CARÁTER RADICALIZADO DO ANIMAL}

O kaléidoscope narrativo de Derrida encontra no "[o] animal que logo sou" sua abertura material para um outro pensamento e uma outra ética - [da] destruição. animot que se repete na diferença da linguagem das coisas além da representação - animot irrepresentável; força animot que não pode ser amansada, adestrada, disciplinada, domesticada, o que Derrida aprofundará nos estudos da desconstrução com o quase conceito animot. Diferença de uma força demoníaca - forças demoníacas da linguagem das coisas que disseminam em sua [in]finitude $a$ vida [mortalista] [do] animot.

Neste momento, seria importante registrar as marcas destas forças [do] animot no pensamento da diferença, seguindo Derrida - mais de uma língua... Com a tentativa de domesticação ${ }^{10}$ da animalidade no homem pela linguagem humana ["Casa"] começa a epopéia dos animais domésticos (SLOTERDIJK, 2000). 0 animal domesticado traduzido no inconsciente do homem humanizado. Para além do caráter criptocatólico das figuras de mediação e representação, soma-se um caráter muito mais violento [violência mítica] de domesticação do inconsciente animot pela linguagem falada ou inconsciente humano [l'inconscient humain (DERRIDA, 2006, p. 165)] - "Humanização da natureza"11. O que está em jogo nessa linguagem humana é o domínio da alma, de sua multiplicidade, precisamente dos animais, sua "monstruosidade" (DERRIDA, 2006, p. 66) que se dissemina em espectros; o que não passava de um certo medo pelos representantes e guardiões da Europa na figura do demônio oriental, estrangeiro por excelência, passa ser um hóspede inoportuno espectral.

O problema [do] animot gira ao redor da alma e suas formas de controle [o animal é o outro em relação aos outros]; sem face, deve ser exterminado frente seu caráter destrutivo, fazendo imperar pela alma seu próprio domínio. O saber filosófico tem tamanha facilidade em reconhecer [o] animot, que mesmo os pastores sabem identificar quais de suas ovelhas foram atingidas por esses espectros. Domínio [sem resistência] da animalidade [do] animot: questão que todo rebanho atento de críticos, céticos e moralistas se colocam desde sua história imemorial. A animalidade do homem abandona o homem do que nele pode haver de humanoa clareira se abre para natureza se transformar num pasto com seus animais domésticos - é ao nomeado "humano" que o pastorado se revela, evocando as vozes do Ser na domesticação [do] animot. A liberdade da alma [do] animot termina assim numa unidade onde ela desaparece como vontade e se realiza como razão; a partir da fidelidade já dominante na unidade da palavra, ser fiel à palavra. A autonomeada humanidade o espera com a antiga fé e o antigo enternecimento - pela glória do Ser, as fogueiras ardiam diariamente em magníficos autos de fé - queimando os perversos animots. Ad majorem gloriam Deji2 $-\mathrm{e}$ os homens se alegraram porque foram conduzidos como rebanho obediente pela palavra. Dixi ${ }^{13}$. $O$ fato de uma forma se converter numa outra forma na repetição do mesmo deixa o nomeado humanismo e o estreitamento do

9 "Satanás sou, e nada do que é humano me é estranho".

10 "Até agora, foi quase o terrível: e por medo quis-se, criou-se e alcançou-se o tipo contrário, o animal doméstico, o animal gregário, o animal doente, o cristão...". Nietzsche. F. Sabedoria para depois de amanhã. Trad. Karina Jannini. São Paulo: Martins Fontes, 2005, p. 296.

11 "Vós quisestes tirar a selvageria do ser humano, mas o enfraquecestes; do lobo fizestes o cão, e do próprio ser humano o melhor animal doméstico do ser humano." Nietzsche. F. Fragmentos do espólio (julho de 1882 a inverno de 1883/1884). Trad. Flávio R. Kothe. Brasília: UnB, 2004, p. 260, 349.

12 "Para maior glória de Deus".

13 "Assim eu disse". 
conceito da existência [do] "ser" determinado mediatamente por meio da cristandade, revelando uma vez mais como a fé cristã se apropriou da metafísica, trazendo seu domínio para o Ocidente; submissão à autoridade de certa ordem que prospere e desenvolva [um] "ser" - uma razão de ser - uma fé para conquistar a vida. Capaz de apaziguar a animalidade [do] animot, transformando-o num animal domesticado, um rebanho tão violento de milhares de milhões, esse domínio sem resistência faz com que as almas se diferenciem na identidade da face. Ele passa mais uma vez no meio da multidão com aquele mesmo semblante humano com que caminhara entre os homens quinze séculos antes. As almas navegam na ideia de um domínio e de um governo superior [pastorado das almas ou governabilidade das almas] - "ser", "verdade" e ideologia caminham em tríade e pertencem-se mutuamente, assim como eles, interpenetrado, pertencem a uma tradição cristã. Essa história imemorial desafia a nomeada humanidade a perceber que, antes de toda relação [do] animot em relação aos poderes e às forças, sua "essência" está introjetada na verdade do ser e sua ideologia. Essa "humanidade" encontra-se em ligação com o "ser". Só o ser é - diriam seus pastores; [o] animot permanece vinculado à história do ser e transforma-se ideologicamente em humano. Neste saber, deve existir um só rebanho e um só pastor... Há um Pastor que conduz este rebanho imenso. De onde vem a crença [no] ser-sentimento oceânico?

Mas no caráter radicalizado [do] animot ocorre algo enigmático, uma perturbação excepcional; aquilo que permanece impensado nesse saber: [a] irritabilidade [do] animot - ato de escutar [o não-sonoro] os ruídos internos. Na verdade, o homem não é um "ser" diverso dos animais ou superior a eles e as funções da alma mais elevadas em nada mudam o fato de que o homem é um animal, no qual a criação superior é inconcebível em si mesma e só podem conceber-se como funções dos instintos animais. Aos nomeados "seres humanos" não se exige uma explicação diferente da dos animais. A "humanidade" é uma comum "espécie" animal entre outras. No nomeado "ser humano" [des] habitam muitos espectros como animais. Por isso, [o] animot não é um falar ou um ser falante, mas uma ação ou pensamento da ação, marcado por diferenças silenciosas. "Falar" de coisas que não são uma "fala", mas pura ação instintual, torna-se, diante desta fala, uma causa missionária, neste falar, com o sério risco de extermínio deste animal ou animais - diferenças demoníacas. Exclusão da percepção do "ser" [seres] que não tem fala [não possuem o poder de nomear]. A animalidade dos animais se torna estranha [estranho]. Os impulsos instintuais mais profundos [do] animot se tornam estranhos ou estão fora da casa da linguagem [fala e imagens arcaicas]. A alma [do] animot habita e não habita a nomeada casa. A experiência passa pelo outro [do outro] que não tem face - animot ou a animalidade no homem. Este caráter radicalizado [do] animot faz desaparecer um complexo de imagens [imago] ou ordem da fala [linguagem humana] no instante de seu instinto [mundo de forças puras $e$ constantes] - [o] animot está sempre com vontade de atear fogo na Casa.

A estrutura da "Casa" é a presunção do nomeado humano diante das forças das figuras da natureza. A estrutura da "Casa" é destruída e desconstruída pelo tremor e terror da linguagem animot. [O] animot faz derreter a imago e a linguagem humana, deixando suas marcas e espaços interiores.

\section{[O] ANIMAL COMO ESCRITURA INTERIOR}

Acreditamos nesse trabalho destas marcas, que esta materialidade estaria numa diferença vinculada $a$ traços e um inconsciente como escritura na resistência frente ao discurso do pensamento metafísico. Estamos aqui - mais de uma língua - nos quase conceitos que se tornam ético-políticos; na relação de Derrida com a psicanálise; a psicanálise sendo uma perturbação; da importância de Freud para o pensamento de Derrida (BENNINGTON, 2004).

O animot, por ser um quase conceito forjado no pensamento da diferença e na psicanálise, pode encontrar uma abertura para fora da clausura metafísica; repete-se entre a diferença noutro quase conceito forjado por Derrida: différance. Quase conceitos em atos que antecedem a linguagem fonemática [inconsciente humano] vinculados à psicanálise e ao pensamento da diferença: animot e différance - que só se distinguem na escritura e não na palavra falada. Podemos encontrar esta diferença no pensamento derridiano em sua estranha escritura interior como resistência $\mathrm{n}$ [o] político. A letra $\boldsymbol{a}$ na escrita da palavra diferença (DERRIDA, s/ data) - poderíamos escrever diferança em português. Claro que o neografismo, como conjunto de princípios da neografia ou de um novo sistema de ortografia, desencadeia um complexo problema no próprio pensamento da diferença. Em francês, "différence" ou "différance" possuem uma semelhança fônica e uma alteridade gráfica instaurada pela troca do $e$ "legítimo" pelo estranho a transgressor, violador 
de uma tradição da linguagem referida à dimensão da voz, do discurso, da fonética. De qualquer maneira, o que Derrida está chamando a atenção é para um texto escrito, ou seja, da diferença gráfica entre o $\boldsymbol{e}$ e o $\boldsymbol{a}$ que funciona no interior de um sistema de escrita, e também funciona no interior de toda uma cultura dos espectros. O a funciona como um espectro; de um aparelho da alma que remete à escritura. A diferança não pertence mais à ordem da sensibilidade, mas, sim, aos registros do pensamento, traços de memória que estão na escrita. A diferença com $a$ é um traçado, uma marca cultural e para além da cultura; a diferança é um espectro se comparado ao espírito revelado da voz. Esta diferança traz pela escritura uma força intensiva que se repete a ser medida no pensamento da diferença e rompendo com a História oficial dos dominantes. [O] animot pode desconstruir $e$ destruir. Com isso, torna-se necessário, como resistência, todo este movimento estratégico destes quase conceitos no pensamento da diferença, para que os mesmos não sejam capturados pelo sistema de representação. Caráter estrangeiro [do] animot, como uma maneira de trabalhar com estas coisas silenciosas no político; consequentemente, abrindo espaço para novas subjetivações e uma ética. 0 quase conceito animot dissolve o sistema harmônico de composições e imagens arcaicas do pensamento da representação. $O$ mundo não é feito só de representações ou não tem seu passe somente pela linguagem humana [“...quem disse que a mensagem da Carta sempre chega ao seu destino?" (DERRIDA, 2007, p. 539, 564)].

Esses deslocamentos [do] animot podem estrategicamente ser linguísticos [linguagem ou língua], [des]habitando uma "Casa" ou não - mas [o] animot não é puramente uma linguagem. Registrar [o] animot na ordem da linguagem, linguagem animal, é pensar [o] animot na linguagem e para além da linguagem, numa relação de forças; quando [o] animot responde, responde já em ato, na cena da escritura como resistência, deixando marcas profundas e interiores; só existe resistência da alma quando a alma [do] animot é constituída na escritura. Retornamos ao animal autobiográfico.

Ser um animal autobiográfico passa pela experiência trágica de afirmação da diferença na escritura. Nesse momento de seu pensamento, Derrida instaura Aquilo que chama animot para além do verbum, revelando sua força numa tradição da escritura que [des]habita a casa da linguagem, deixando profundas marcas; nesse habitar e não habitar - está entre - come por dentro, como numa antropofagia animot. Experiência renovada; [o] animot instaura a experiência do drama trágico no interior do nomeado ser desconstruindo o mesmo, frente uma repetição do mesmo... [O] inconsciente como escritura faz a alma resistir à habitação do nomeado "Ser", tornando-a inabitável para este - a alma como deserto não é habitável pelo ser - é alma inabitável que resiste ao "Ser". Queremos dizer com isso que a desconstrução do nomeado "Ser" tem sua passagem [pelo] animot pensado em sua alteridade radical [outro do outro sem face] - é que os ventos que vêm do interior [do] animot disseram-te baixinho o ardor da liberdade; é que esse excessivo arquejo feriu tua jovem face, humana em demasia; é que, muitas vezes, o Poeta responde pelo animal; é que em tempos imemoriais, foram expulsos da Casa; é que a negra força [do] animot responde em infernos uivos; é que [o] animot conhece o terror; é que em cada coisa aberta pulsa uma pré-coisa; é que trata-se de tornar a alma monstruosa; é que é preciso ser vidente, fazer-se vidente; é que os primeiros românticos [Novalis] foram videntes; é que a trilha branca em face, a interpelar, como um rebanho que pastasse; é que hordas hostis de uivos sicários evocam [o] animot; é que erguem-se a rosnar como gatos loucos; é que ao roçarem na palha os seus membros se excitam; é que os meninos refletidos em sua face vão sempre à Igreja; é que por sua virgindade, pureza da face, agora e no futuro; é que sofreram convulsões que foram as mais triunfantes frente a face humana; é que a voz de cem corvos acompanha [o] animot; é que mil lobos carregam esta religiosa tarde de voragem; é que mil sementes selvagens disseminam [o] pólen; é que as coisas inauditas e inomináveis não habitam sua face; é que uiva [o] lobo na desconstrução e não [sua] face; é que o boi refreia seus instintos; é que nossas nádegas não são as delas; é que adormecido inseto forte; é que sua literatura ainda passa pelo saber filosófico [da face]; é que [o] animot de Derrida é transformação em realidade reafirmação de sua obra - Aquilo que existe dentro de Derrida sobe à tona; é que os poetas são irmãos [...].

Guardemos silêncio. Eu te conheço e te admiro em silêncio. Tua face demasiada humana. Por isso, antes de chegar à linguagem, passa-se por um estreito de um horror extraordinário, chamado Ponte do Demônio, trabalhando furiosamente em ações destrutivas como numa narrativa. Como coisa da natureza, [o] animot não tem a menor consciência de seu ato; as coisas neste mundo são mudas e efetuam seu trabalho int[f]erno silenciosamente e, com isso, um animot ainda mais terrível [tudo é permitido para o animal].

A radicalização deste quase conceito - animot - no pensamento da diferença faz tremer a metafísica da "Casa" [linguagem] onde habita o nomeado humano. Com uma perturbação da alma - exaltado - [o] animot 
tem o terrível encontro com a mensagem da Carta. [O] animot rasga sua mensagem - e todos os animais amavam-se em seu Deus.

Recebido em: 5 de janeiro de 2015. Aprovado em: 29 de junho de 2015.

\section{REFERÊNCIAS}

Benjamin, W. Le Caractère destructeur (1931). Traduit Rainer Rochlitz. In: Oeuvres II. Paris: Gallimard, 2000.

. Sur le langage en général et sur le langage humain (1916). Traduit Maurice de Gandillac. In: Oeuvres I. Paris: Gallimard, 2000.

Bennington. G. Entrevista com Geoffrey Bennington. In: Duque-Estrada, P.C. Desconstrução e ética: ecos de Jacques Derrida. Rio de Janeiro: PUC/Rio; São Paulo: Loyola, 2004.

Birman, J. Freud e a política, entre judaísmo e judeidade. In: Said. E. W. Freud e os Não-Europeus. Trad. Arlene Clemesha. São Paulo: Boitempo, 2004.

Derrida, J. L'animal que donc je suis (1999) Paris: Galilée, 2006.

Margens da filosofia. Trad. Joaquim Torres Costa e António M. Magalhães. Porto: Rés, s/ data. O animal que logo sou (A seguir). (Parte 1) Trad. Fábio Landa. São Paulo: UNESP, 2002.

O Cartão-postal: de Sócrates a Freud e além. Trad. Simone Perelson e Ana Valéria Lessa. Rio de Janeiro: Civilização Brasileira, 2007.

Duque-Estrada, P. C. Derrida e a crítica heideggeriana do humanismo. In Jacques Derrida: pensar a desconstrução. São Paulo: Estação Liberdade, 2005.

Ferenczi, S. Adestramento de um cavalo selvagem. Trad. Álvaro Cabral. São Paulo: Martins Fontes, 2011. (Psicanálise II, Obras completas, 2).

Freud, S. Más allá del principio de placer (1920). Trad. José L. Etcheverry. Buenos Aires / Madrid: Amorrortu, 2008. (Obras completas, 18).

LACAN, J. Le stade du miroir comme formateur de la fonction du Je (1936-1949) In: ___ _ Écrits. Paris: Seuil, 1966.

Nietzsche. F. Fragmentos do espólio (julho de 1882 a inverno de 1883/1884). Trad. Flávio R. Kothe. Brasília: UnB, 2004.

Sabedoria para depois de amanhã. Trad. Karina Jannini. São Paulo: Martins Fontes, 2005.

Novalis. Pólen: fragmentos, diálogos, monólogo. Trad. Rubens Rodrigues Torres Filho. São Paulo: lluminuras, 2009.

rimbaud, A. Correspondência. Trad. Ivo Barroso. Rio de Janeiro: Topbooks, 2009.

Sloterdijk. P. Regras para o parque humano: uma resposta à Carta de Heidegger sobre o humanismo. Trad. José Oscar de Almeida Marques. São Paulo: Estação Liberdade, 2000.

João C. Galvão Jr. galvao2112@bol.com.br 